\title{
Preparation of $E$-1,3-diaminoethenyl functional groups by the reaction of enol tosylate of alpha-formylglycine with primary and secondary amines
}

\author{
Sitaram Bhavaraju ${ }^{* \dagger}$
}

51 Lower College Road, Dept. of Chemistry, University of Rhode Island, Kingston, RI-02881, USA

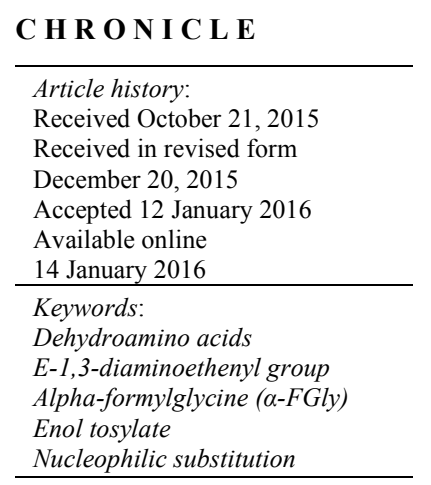

\begin{abstract}
A B S T R A C T
The $E$-1,3-diaminoethenyl functional group is a potentially useful synthon. A number of examples of $E$-1,3-diaminoethenyl functional groups were prepared in good yield starting from an $E$-enol tosylate of a serine based diketopiperazine and $1^{\circ}$ - or $2^{\circ}$ amine nucleophiles. The reaction proceeds via a stereoselective nucleophilic substitution pathway.
\end{abstract}

\section{Introduction}

An excellent review of naturally occurring peptides containing $\alpha, \beta$-dehydro amino acids has been published. ${ }^{1}$ The isolation of Callynormine A, marine metabolite from the Kenyan sponges Callyspongia abnormis has been reported. ${ }^{2}$ Callynormine $\mathrm{A}$, appears as a rare $\mathrm{N}$-atom containing compound with a potent beta turn mimetic and was classified as cyclic endiamino peptide and the structure of this natural product was confirmed by NMR and X-ray analysis. It was also shown that the structural unit $\alpha$-amido$\beta$-aminoacrylamide functionality (1,3-diaminoethenyl) was used to introduce structural and conformal rigidity in these cyclic heterodetic peptides possibly through a $\beta$-turn mimetic. 1,3-Diaminoethenyl functional groups also play an important role in the human arylsulfatase enzyme regulations wherein the 1,3-diaminoethenyl groups manifests as alpha formyl glycine ( $\alpha$-FGly), via a serine or cysteine residue based modification structurally supported by hydrogen bonding. 3-6 1,3-Diaminoethenyl functional groups (Fig.1), are thus an interesting class of synthons, and efforts to make these have been found challenging and limited success has been reported so far.

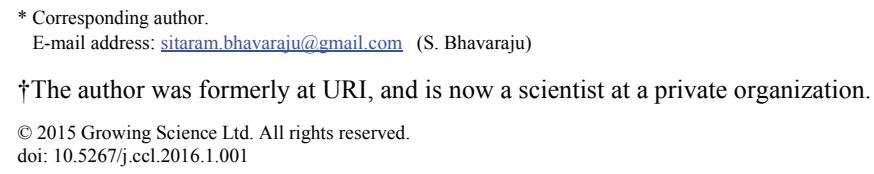




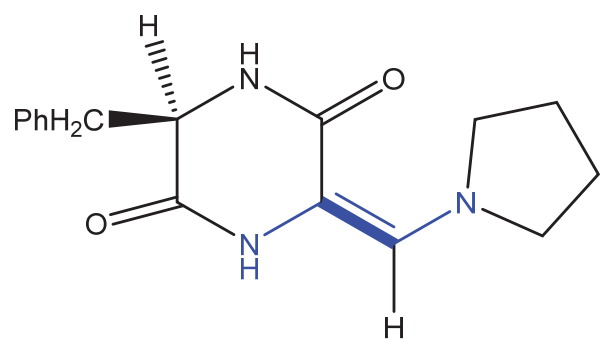

Fig. 1. An example of $E$-1,3-diaminoethenyl functional group

Intrigued by the aforementioned structural features of 1,3-diaminoethenyl bonds, we looked into their availability as synthons. Literature attempts to make 1,3-diaminoethenyl functional groups by the reaction of the enol tosylate of $\alpha$-FGly with amines were largely unsuccessful except when the enol tosylate used as the synthetic precursor was usually acyclic and had the support of an ester functionality. ${ }^{7-10}$

Nakazawa et al., ${ }^{7}$ were the first group to study the formation of dehydroamino acids via tosylhydroserine. By using modified Moffat conditions for oxidizing the serine alcohol to its tosylate, and then reacting it with a nucleophile such as methyl amine they could obtain the 1,3-diaminoethenyl functional group. However, when dimethyl amine was used, a retro aldol product was obtained.

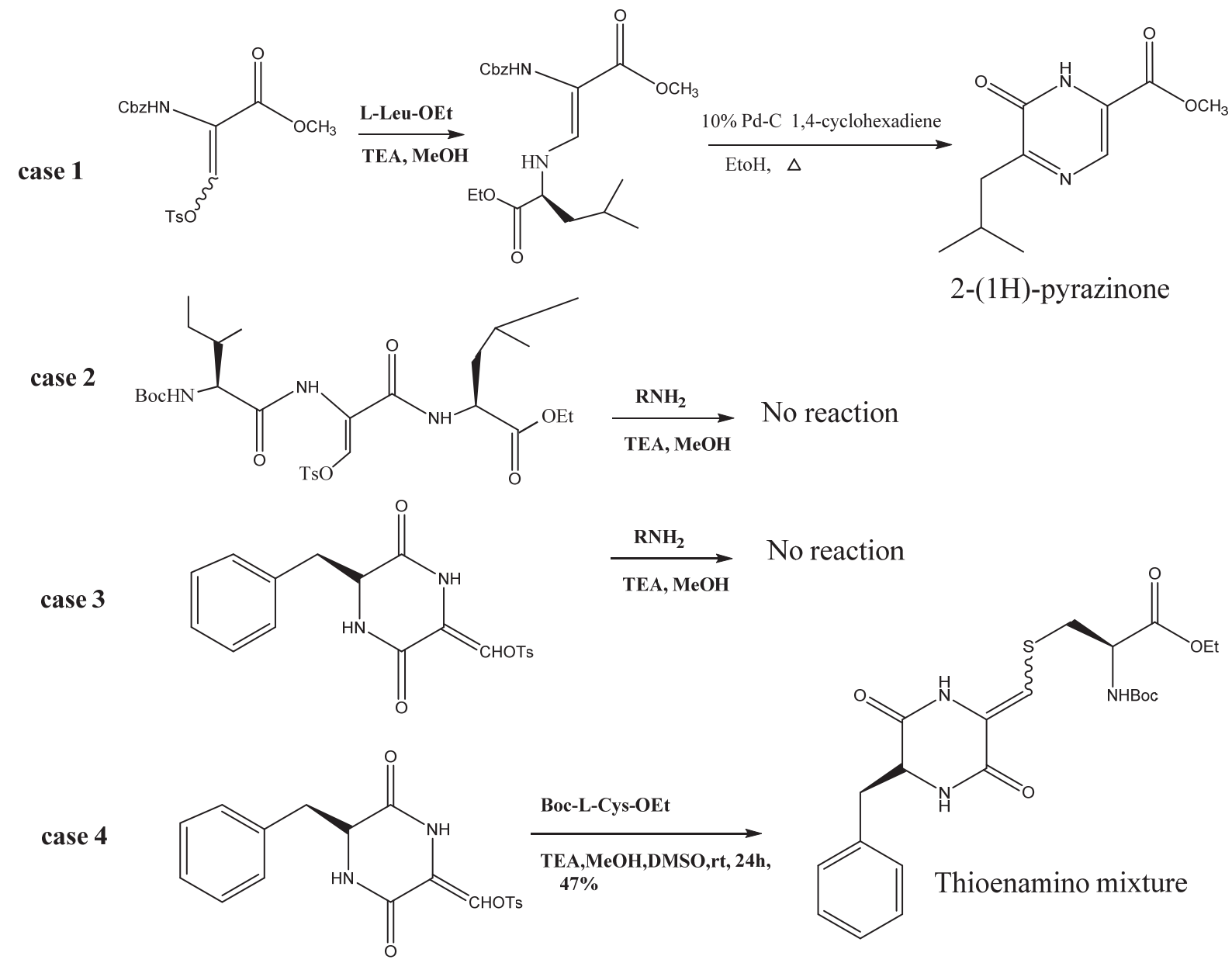

Scheme 1. Literature attempts to prepare 1,3-diaminoethenyl functional groups 
Scheme 1, shows the various synthetic attempts in the literature to prepare 1,3-diaminoethenyl bonds. Kashman et al., ${ }^{8}$ attempted the preparation of 1,3-diaminoethenyl peptides using the enol tosylate of a protected peptide resulting in a highly unstable and air sensitive derivative that was converted to the product 2-(1H)-pyrazinone (Scheme 1, case 1). Kashman et al., ${ }^{9}$ published their attempted trials on the reaction of amines with the peptides amides of some enol tosylates and were unsuccessful in forming 1,3-diaminoethenyl peptides, although some thioenamine mixture may have been produced as evidenced by proton and carbon NMR (Scheme 1, case $2,3 \& 4$ ).

An independent US patent does exist in the literature for the preparation of 1,3-diaminoethenyl bonds via cysteine modifications having linear structural supports only. ${ }^{10}$

The above brief literature review implies that the formation of 1,3-diaminoethenyl bonds is an important synthetic endeavor. Considering the interesting synthetic challenges in making 1,3diaminoethenyl functional groups we have embarked on making bonds of such nature. The reactions of amines with an enol tosylate of $\alpha$-FGly that has the support of a cyclic amide have been reported to be unfavorable but in our hands we have had some success and we now report the synthetic details leading to 1,3-diaminoethenyl functional groups.

\section{Results and Discussion}

The serine based diketopiperazine L-Phe-L-Ser-DKP was used as a surrogate to make 1,3diaminoethenyl functional groups. Several unsuccessful attempts were made by us to oxidize the serine based diketopiperazine (DKP) primary alcohol with a series of conventional oxidants. These numerous attempts were unsuccessful, because the desired aldehyde was unstable to isolation. Eventually, the enol tosylate of the aldehyde could be prepared and trapped employing a modified Moffat oxidation as shown in scheme 2 .

We have improved the synthetic yield of the $E-1$ to $>80 \%$ when compared to literature procedures. ${ }^{9}$ The enol tosylate $E$-1 was obtained using simple methodology and required no chromatographic purification. The characteristic ${ }^{1} \mathrm{H}-\mathrm{NMR}$ chemical shifts associated with $E$ - 1 include the vinyl center at about $6.4 \mathrm{ppm}$ and the chiral proton at about $4.3 \mathrm{ppm}$.

Furthermore, these two characteristic proton shifts served as markers for monitoring of the reaction of the starting material enol tosylate with amines. Additionally, the $E-\mathbf{1}$ stereochemistry had been established by us previously based upon the reciprocal NOE obtained between the vinyl-proton and hydrogen bonded amide resonance $10.2 \mathrm{ppm}$ in the NMR solvent DMSO- $\mathrm{d}_{6}$.

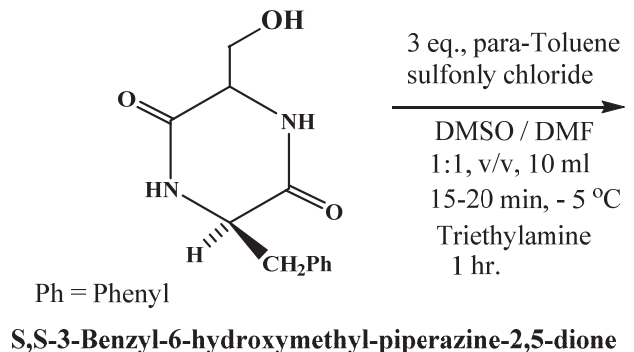

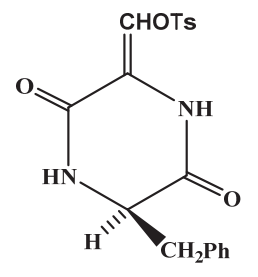

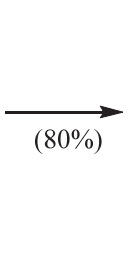

E-enol-tosylate of S-3-benzyl-6-formylpiperazine-2,5-dione

Scheme 2: Oxidation of DKP alcohol to enol tosylate

This article describes the successful reaction of neutral nucleophiles like $1^{\circ}$ - and $2^{\circ}$-amines with the $E$-enol tosylate of an $\alpha$-FGly (1) that has the support of a cyclic amide to give $E$-1,3-diaminoethenyl functional groups stereo-selectively. The reaction of butanethiol as a sulfur nucleophile provides the $E$ - 
thioenamine functional group in a similar manner (Scheme 3). The reaction profile is discussed in detail.
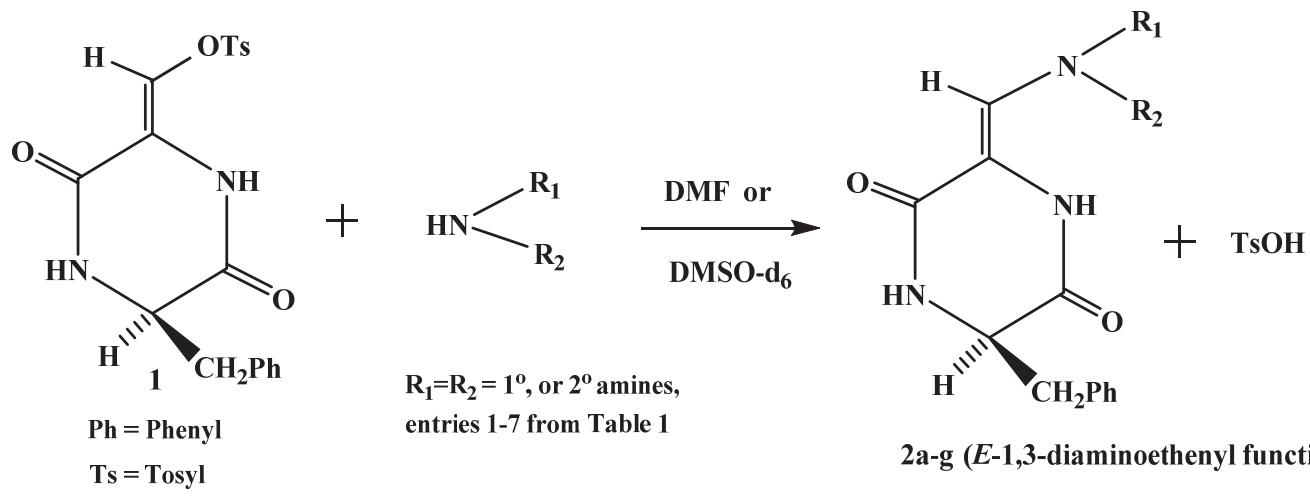

entries 1-7 from Table 1

2a-g (E-1,3-diaminoethenyl functional groups)

\section{(1)}

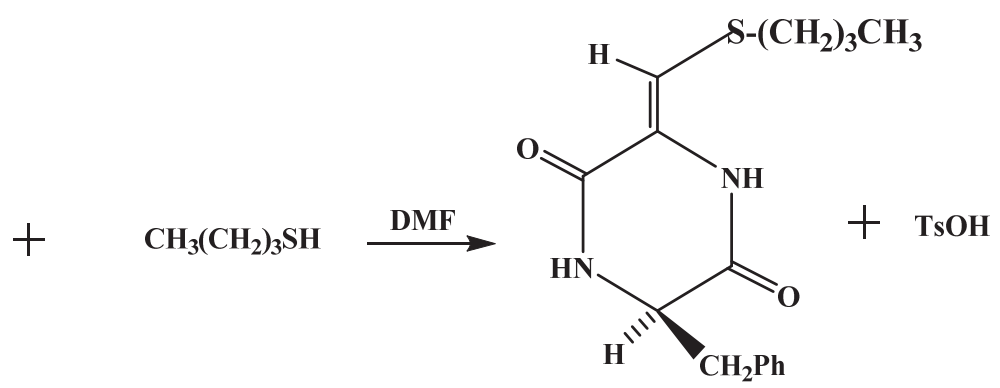

$2 \mathrm{~h}$ (thioenamine functional group)

Scheme 3: Reaction of enol tosylate with amines and butanethiol

We had previously communicated on the mechanism of nucleophilic attack on the $E$-enol tosylate (1) by amines, to deliver $E$-1,3-diaminoethenyl products stereo-selectively. ${ }^{11}$ The detailed mechanism observable via the usage of ${ }^{1} \mathrm{H}$ NMR spectroscopy allowed us to expand our knowledge on the formation of 1,3-diaminoethenyl products. The operating mechanism includes the initiation of the reaction by deprotonation or chemical exchange of $E-1$ by the amine with subsequent reprotonation to more stable anionic tautomers (1a-d) possible through hydrogen bonded assistance in a polar aprotic solvent. This leads to a nucleophilic substitution giving rise to 1,3-diaminoethenyl products with $E$ stereochemistry consistently in all of our reactions with $1^{\circ}$ and $2^{\circ}$ amines (Scheme 4 ). In our hands no evidence was seen for any Z-1,3-diaminoethenyl products.

Table 1. Synthesis of 1,3-diaminoethenyl functional groups and an Thioenamine functional group via scheme 3.

\begin{tabular}{lllcc}
\hline Entry & Amine & Conditions & Product & Yield\% \\
\hline 1 & Pyrrolidine & 5 eq., DMF, 5 hr., r.t. & 2a & 40 \\
2 & Piperidine & 5.5 eq., DMF, 10 hr., r.t. & $\mathbf{2 b}$ & 25 \\
3 & Dipropylamine & 8 eq., DMF, 9 days, r.t. & $\mathbf{2 c}$ & 70 \\
4 & Ethylenediamine & 4.5 eq., DMSO-d6, 3days, r.t. & $\mathbf{2 d}$ & a \\
5 & Piperazine & 2.75 eq., DMSO-d6, 6 hr., r.t. & $\mathbf{2 e}$ & a \\
6 & Tert-butylamine & 12 eq., DMF, $1.5 \mathrm{hr}$., reflux & $\mathbf{2 f}$ & 60 \\
7 & Aniline & 10 eq., DMF, 6 hr., reflux & $\mathbf{2 g}$ & 84 \\
8 & Butanethiol & 12 eq., DMF, 6 days, $110^{\circ} \mathrm{C}$ & $\mathbf{2 h}$ & 30 \\
\hline
\end{tabular}

\footnotetext{
${ }^{\mathrm{a}}$ reaction carried out in a 5-mm NMR tube, monitored for $100 \%$ product formation using
}

${ }^{1} \mathrm{H}-\mathrm{NMR}$ on a $400 \mathrm{MHz}$ instrument; r.t.= room temperature 
While our previous communication focused on the mechanism, this article details the synthesis and characterization of the 1,3-diaminoethenyl compounds and a thioenamine. Table 1, summarizes the reaction conditions. Some of these reactions occurred at room temperature thereby enabling us to monitor them using ${ }^{1} \mathrm{H}-\mathrm{NMR}$ and gave quantitative formation of the 1,3-diaminoethenyl product.

We used pyrrolidine as the first cyclic amine to react with enol tosylate. It was determined by ${ }^{1} \mathrm{H}$ NMR studies that the reaction proceeds with 5 equivalents of amine at room temperature and was complete in 5 hours, exhibiting bimolecular kinetics. The second order rate constant $\mathrm{k}=1.37 \mathrm{l} / \mathrm{mol}-\mathrm{hr}$ was determined by NMR time course studies by monitoring the integral of the vinyl resonance (measure of concentration) versus time.
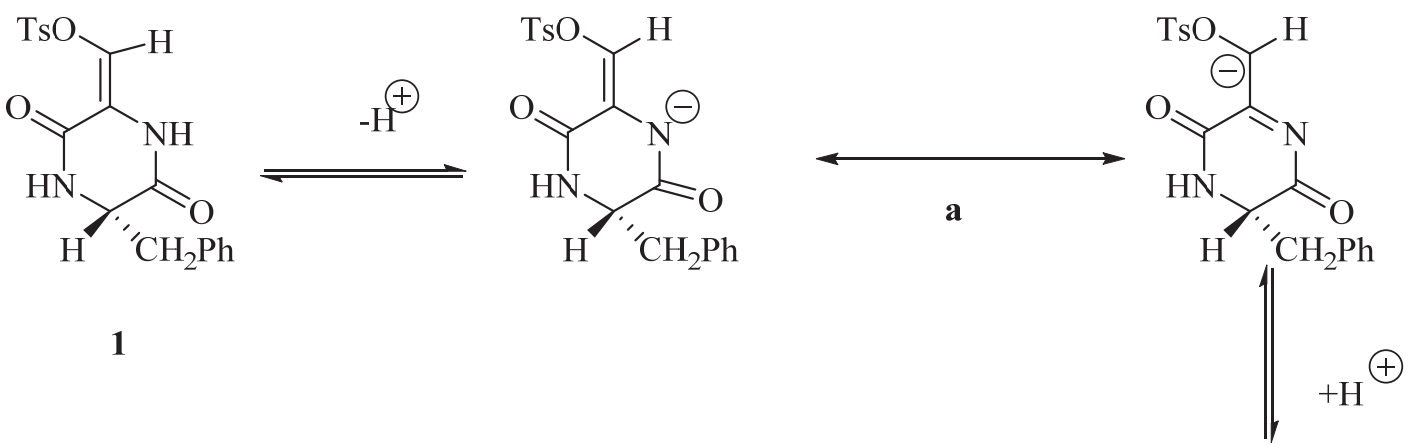<smiles>Oc1nc(O)c(Cc2ccccc2)nc1O</smiles>

d
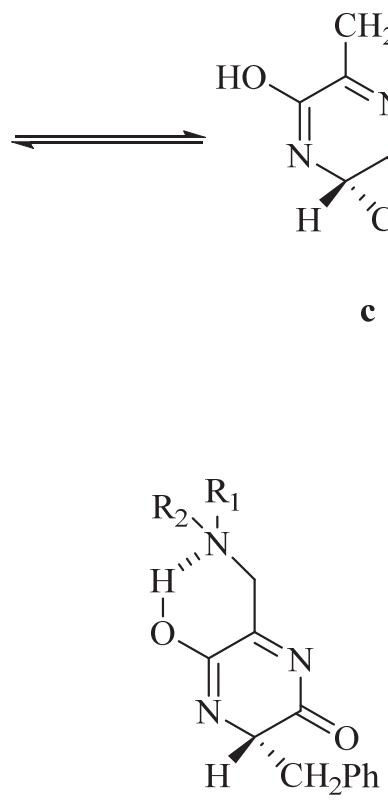

e<smiles>[2H][C@@H]1N=C(O)C(=O)N=C1CO[Na]</smiles>

c<smiles>[2H][C@@H]1C(=O)NC(=O)N=C1CO[Na]</smiles>

b

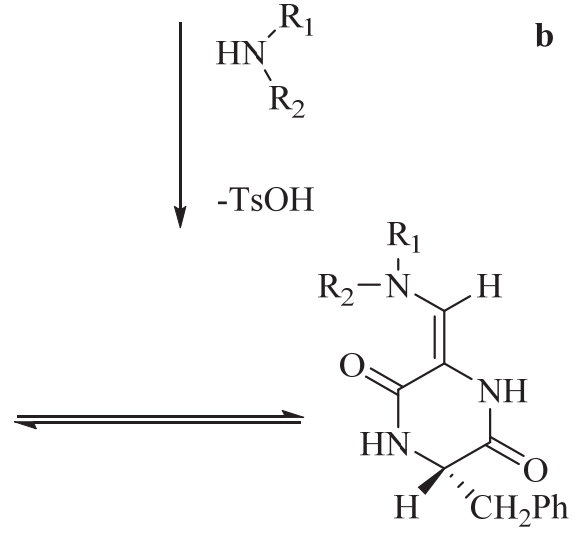

2a-g

Scheme 4: Reaction mechanism of enol tosylate with amines as revealed by time course ${ }^{1} \mathrm{H}$ NMR experiments ${ }^{11}$

1,3-Diaminoethenyl product $\mathbf{2 a}$ exhibited characteristic resonances in the proton spectrum at $\delta 6.43$ ppm and $3.99 \mathrm{ppm}$, assigned to vinyl and chiral protons, respectively. The two amide resonances appeared at $\delta 7.30 \mathrm{ppm}$ and $8.90 \mathrm{ppm}$. Reciprocal NOE were obtained between the vinyl proton and the amide proton $8.90 \mathrm{ppm}$, confirming the stereochemistry at the double bond center to $E$-stereoisomer, determined in the NMR solvent DMSO- $\mathrm{d}_{6}$. The mass spectrum was obtained using direct insertion/MS and the molecular ion, $\mathrm{M}^{+}$was detected at $285 \mathrm{~m} / \mathrm{z}$. 
The reaction between enol tosylate and piperidine proceeded smoothly with the use of 5.5 equivalents of amine with stirring at room temperature, and was complete in 10 hours. The characteristic color transition from light brown at the start of the reaction to a deep brown red towards the end, indicated the completion of the reaction. 1,3-diaminoethenyl product $\mathbf{2} \mathbf{b}$ was isolated by quenching the reaction mixture with ice. The vinyl proton and carbon resonances for the 1,3diaminoethenyl functional group appeared at $\delta 6.19 \mathrm{ppm}$ and $102.79 \mathrm{ppm}$ in the corresponding proton and carbon spectra, recorded in the NMR solvent DMSO- $\mathrm{d}_{6}$. The ESI/MS mass spectrum resulted in a molecular ion peak $[\mathrm{M}+\mathrm{H}]^{+}$at $300.1 \mathrm{~m} / \mathrm{z}$, and an $[\mathrm{M}+\mathrm{Na}]^{+}$peak at $322.1 \mathrm{~m} / \mathrm{z}$.

Dipropylamine was the only secondary acyclic amine that was successfully reacted. The reaction was facilitated by the usage of at least 8 equivalents of the amine with respect to the tosylate under room temperature conditions. Initial reaction runs with reaction times ranging from 24 hours to 2 days resulted in the disappearance of the amine proton at $10.2 \mathrm{ppm}$ associated with the hydrogen bonded amide of the starting tosylate. The reaction took 9 days for quantitative formation of the product as evidenced by the time course ${ }^{1} \mathrm{H}$ NMR spectroscopic studies using DMSO- $\mathrm{d}_{6}$ as NMR solvent. The reaction exhibited no change in the vinyl proton chemical shift resonance observed at $\delta 6.43 \mathrm{ppm}$ (time $=0$ to 24 hours).

After 48 hours of reaction time an important observable feature in this study is the formation of a new vinyl center at $6.46 \mathrm{ppm}$ associated with the product which falls very close to the vinyl center at $6.43 \mathrm{ppm}$ of the starting tosylate. Eventually after $(\mathrm{t}=9$ days $)$ the reaction reached completion and the new vinyl center for the 1,3-diaminoethenyl product appeared at $\delta 6.43 \mathrm{ppm}$. Monitoring these subtle changes in proton chemical shifts allowed us to carefully follow the progress of this reaction to successful completion using ${ }^{1} \mathrm{H}-\mathrm{NMR}$. The other notable chemical shift change was associated with the chiral center proton which shifted from $4.31 \mathrm{ppm}$ in the starting tosylate to $3.96 \mathrm{ppm}$ in the product. A plot of the diminishing integral value associated with the concentration of vinyl proton versus increase in time and in the presence of an excess of the amine exhibited pseudo first order dependence. The rate constant for this reaction was determined to be $1.45 \times 10^{-3}$ moles/hour.

A direct insertion/MS of a sample of the 1,3-diaminoethenyl product (2c) resulted in the $\mathrm{M}^{+}$, molecular ion at $315 \mathrm{~m} / \mathrm{z}$. Other prominent peaks observed in this spectrum are positioned at 91,224 , and $286 \mathrm{~m} / \mathrm{z}$, respectively.

The reaction of a large excess of t-butyl amine with the enol tosylate was attempted at room temperature using ${ }^{1} \mathrm{H}-\mathrm{NMR}$ to monitor the reaction but the only result was the disappearance of amide $(\mathrm{NH})$ proton at $10.28 \mathrm{ppm}$. A small amount of product formation was observed when the reaction was carried out at $143{ }^{\circ} \mathrm{C}$ for 2 hours, with 10 equivalents of amine. The reaction was optimized by using 12 equivalents at a reflux temperature of $153{ }^{\circ} \mathrm{C}$ for 1.5 hours in the solvent dimethyl formamide. Based on these reaction conditions it can be said that the reaction of enol tosylate with sterically bulky primary amines like tert-butylamine is extremely slow at room temperature and is slow even at elevated temperatures with a large excess of the primary amine. 1,3-Diaminoethenyl product (2f) had characteristic vinyl resonances at $\delta 6.38(\mathrm{~d})$, and $100.71 \mathrm{ppm}$ in the corresponding proton and carbon spectra, respectively. GC/MS analysis of this compound gave the $\mathrm{M}^{+}$, molecular ion at $287 \mathrm{~m} / \mathrm{z}$. Other major peaks associated with the fragmentation appear at $29,41,57,91,140,196$, and $272 \mathrm{~m} / \mathrm{z}$, respectively.

Aniline, an aromatic $1^{\circ}$-amine, was used in excess and reacted with enol tosylate. The reaction proceeded well only at elevated temperature. Efforts were made to limit the ratio of aniline, increasing reaction time, altering the temperature, or both, but this resulted in products co-precipitating or decomposing. The reaction could be optimized using 10 equivalents of aniline under reflux conditions for 6 hours. The sluggish reaction in this case is attributed to the nature of nucleophile as was the absence of useful reaction in the case with t-butylamine. While $1^{\circ}$-amines require elevated temperatures 
to react, $2^{\circ}$-amines react rather well at room temperature. 1,3-diaminoethenyl product (2g) showed characteristic vinyl resonances at $\delta 6.78(\mathrm{~d})$, and $106.19 \mathrm{ppm}$ in the corresponding proton and carbon spectra, respectively. The GC/MS analysis for this product showed the $\mathrm{M}^{+}$, molecular ion peak centered at $\mathrm{m} / \mathrm{z} 307$. Further, the fragmentation patterns arising from the parent molecular ion source showed peaks at $\mathrm{m} / \mathrm{z} 28,77,91,104,131,161,187$, and 216.

Ethylenediamine a di-amine, successfully reacted at room temperature. Reaction trials included a gradual increase in the equivalents of amine with respect to the tosylate over a range of shorter to longer reaction times. At shorter reaction times such as between 1-5 hours and with the usage of up to 5 equivalents of diamine, we only observed the disappearance of the amide proton at $10.27 \mathrm{ppm}$ from the starting tosylate. Upon longer reaction times such attempts often led to reactions wherein the product was not isolable in our hands. However using ${ }^{1} \mathrm{H}$ NMR we observed that ethylenediamine does react with the tosylate, slowly over a period of 3 days at room temperature and 4.5 equivalent of di-amine was needed to complete the conversion of the starting tosylate to the product. Experimentally, in a NMR tube, $0.083 \mathrm{mmol}$ of the starting tosylate was dissolved in $0.7 \mathrm{ml}$ of deuterated dimethyl sulfoxide. To this $25 \mu \mathrm{L}$ of ethylenediamine was added in one portion and the reaction was followed using ${ }^{1} \mathrm{H}$ - NMR. After 2 hours, the recorded ${ }^{1} \mathrm{H}$ NMR spectrum showed a new signal at about $6.28 \mathrm{ppm}$ as a doublet in the neighborhood of the vinyl signal at $6.23 \mathrm{ppm}$ associated with the starting tosylate. During this time period, the chiral center at $4.3 \mathrm{ppm}$ also had an evolving neighbor at $4.18 \mathrm{ppm}$, associated with product formation. These new signals at $6.28 \mathrm{ppm}$ and $4.18 \mathrm{ppm}$ continued to grow in intensity over 3 days and these were assigned to the new vinyl center and a new chiral proton for the end product. The reaction took 60 hours to complete as evidenced by the absence of any starting tosylate peaks and the sole formation of the 1,3-diaminoethenyl product (2d) as judged by the recorded ${ }^{1} \mathrm{H}$ and ${ }^{13} \mathrm{C}$ NMR spectra.

Piperazine was another di-amine that reacted at room temperature. Efforts to isolate the reaction product were unsuccessful as the 1,3-diaminoethenyl product was highly soluble in water. Attempts to either extract and or separate the product by chromatography lead to product decomposition during our trials. However this reaction can be successfully carried out and monitored using NMR to detect product formation. The reaction took 6 hours for completion as judged by the recorded ${ }^{1} \mathrm{H}$ NMR spectra. For the 1,3-diaminoethenyl product (2e) two characteristic chemical shifts were noted. The signal at $6.13 \mathrm{ppm}$ was assigned to the new vinyl center and the signal at $4.07 \mathrm{ppm}$ was assigned to the new chiral center.

Butanethiol was the only sulfur based nucleophile that reacted successfully. At least 12 equivalents of the thiol with respect to the tosylate (1) were necessary to initiate the reaction at a temperature of $110^{\circ} \mathrm{C}$ over 6 days. Any attempts to lower the thiol ratio though maintaining an excess with respect to starting tosylate at this elevated temperature resulted in the isolation of a mixture of the starting tosylate and the product thioenamine. The conditions necessary for the activation of this reaction mixture at 110 ${ }^{\circ} \mathrm{C}$ and the requirement of longer reaction times are highly indicative of the sluggish nature of the reaction at the double bond center for the substitution of the tosylate, when treated with a sulfur nucleophile. The product thioenamine had a characteristic vinyl resonance at about $6.16 \mathrm{ppm}$ and 115.0 ppm in the corresponding proton and carbon spectra. To our knowledge this is the first direct evidence in the literature where the product thioenamine formation is isolated in $E$-stereochemistry, as we didn't find any signals for other isomer in both proton and carbon NMR. For example, an thioenamine geometric mixture (7:3) as determined by ${ }^{1} \mathrm{H}$ and ${ }^{13} \mathrm{C}$ NMR was reported by Kashman etal ${ }^{9}$ when they used a protected L-Cys-ethyl ester as a nucleophile to react with our surrogate (1). Product thioenamine (2h) had characteristic vinyl chemical shifts at $\delta 6.16$, and $115.0 \mathrm{ppm}$ in the corresponding proton and carbon spectra, respectively. The GC/MS mass spectrum of the thioenamine resulted in major peaks at $304,271,213,129,91,57,41$ and $29 \mathrm{~m} / \mathrm{z}$. The $\mathrm{M}^{+}$, molecular ion peak is centered at 304 . Initially a loss of benzyl cation from the molecular ion peak occurs, accounting for the fragments at $\mathrm{m} / \mathrm{z} 213$ and 
91,respectively. Further the peaks at 57, 41, and 29 are assigned to the fragmentation of the part of the molecular ion originating with the thiol fragment, mainly through the loss of alkyl chains.

Reaction of several other carbon, phosphorus and nitrogen containing nucleophiles were also attempted. Negatively charged nucleophiles such as cyanide, azide, and triphenylphosphite gave no reaction. At room temperatures these nucleophiles were unreactive, while at elevated temperatures only decomposition was observed.

\section{Conclusions}

The reaction between enol tosylate our surrogate (1) that have cyclic support, and amines is reported as unfavourable in the literature. The loss of reactivity at the double bond centre is mainly attributed to the amidation of the carboxylic acid groups. The above reaction summaries clearly demonstrate the successful reactivity pattern of (1) and its ability to react with $1^{\circ}$ and $2^{\circ}$ amines, and a thiol. Through a nucleophilic substitution, the reaction produces exclusively and stereo-selectively E-1,3diaminoethenyl functional groups, as judged by NMR and Mass spectral analyses. Cyclic secondary amines such as pyrrolidine, piperidine, and piperazine reacted well at room temperature and are usually faster when compared to acyclic amines such as dipropylamine and ethylenediamine. An exclusive thioenamine was also synthesized using butanethiol as a sulfur nucleophile. 1,3-Diaminoethenyl bonds of this nature continue to interest the chemical community as they are useful in enzyme regulation and inducing conformational rigidity in peptides.

\section{Acknowledgements}

The author acknowledges the support of partial funding for this work by URI research foundation, and URI Chemistry Dept. Thanks to Prof. William Rosen and Lecturer Dr. Mike McGregor, Chemistry Dept. at URI, for helpful discussions during the course of this endeavor, and for help with NOE acquisitions, respectively.

\section{Experimental}

\subsection{Materials and Methods}

${ }^{1} \mathrm{H}$ and ${ }^{13} \mathrm{C}$ NMR spectra were recorded on a JEOL 400 NMR instrument operating at 400 and 100 $\mathrm{MHz}$, respectively. Decoupling proton experiments were acquired on BRUKER AM $300 \mathrm{MHz}$. All spectra were recorded using DMSO- $\mathrm{d}_{6}$ as the NMR solvent. Proton and carbon spectra were referenced to $\delta 2.50$ and $39.50 \mathrm{ppm}$. Reaction products $(\mathbf{2 a - h})$ were characterized by ${ }^{1} \mathrm{H}$ and ${ }^{13} \mathrm{C} \mathrm{NMR}$, and by Mass spectrometry and or GC/MS. Nuclear Overhauser (NOE) experiments were performed after measuring the necessary T1 relaxation for the protons under study. A Finnigan TSQ instrument with a direct probe insertion module, a Mariner ESI/MS, and GC/MS from HP, were used to determine mass measurements. Optical rotations were measured by using either Rudolph Autopol III or Polyscience SR-6 polarimeter. Melting points are obtained using MEL-TEMP capillary melting point apparatus and are uncorrected. All solvents and amines were distilled prior to use and stored under nitrogen. All solvent, reagents, and amines were purchased from Sigma Aldrich USA, and are ACS reagent grade.

\subsection{General procedure; and 4.3 Physical and Spectral Data}

\section{Synthesis of E-enol tosylate of S-3-benzyl-6-formyl piperazine-2,5-dione, (1)}

$0.468 \mathrm{~g}(2 \mathrm{mmol})$ of the DKP S-3-benzyl-6-hydroxy-methyl-piperazine-2,5-dione was taken in a 50 $\mathrm{ml}$ round bottom flask, dissolved in $26 \mathrm{ml}$ of hot tertiary butanol $\left(50^{\circ} \mathrm{C}\right)$ and $1.8 \mathrm{~g}$ of $4 \AA$ molecular sieves was added to this and stored overnight. The molecular sieves were removed and solvent was 
evaporated to obtain a solid. This solid was taken into a $50 \mathrm{ml}$ round bottom flask and was dissolved in $10 \mathrm{ml}$ distilled dimethylformamide and the flask was maintained on an ice bath at $-5{ }^{\circ} \mathrm{C}$ under nitrogen. To this was added $1.98 \mathrm{~g}(5 \mathrm{mmol})$ of the activator para-toluene sulfonyl chloride, which was previously dissolved in (1:1) mixture of $5 \mathrm{ml}$ each of dimethyl formamide solvent and dimethyl sulfoxide which acts as the oxidant. Stirred for 25 minutes and added triethylamine $4 \mathrm{ml}$ (15 mmol). A dark coloration prevailed in the reaction mixture. The reaction flask was further maintained still at $-5^{\circ} \mathrm{C}$ under nitrogen for an additional 5 minutes. The contents in the flask were continuously stirred under nitrogen atmosphere while it warmed to room temperature for additional 1 hour. The reaction mixture was quenched by pouring to a pre cooled ice water $100 \mathrm{ml}$ and allowed for the solids within 1 hour to precipitate. The obtained solid product was filtered and washed with additional $25 \mathrm{ml}$ cold water and air dried to yield the enol tosylate (1) in $80 \%$ yield. Melting Point $246-248^{\circ} \mathrm{C}$. $[\alpha]_{\mathrm{D}}{ }^{21}=-80.7^{\circ}(c 0.1$, DMSO)

${ }^{1} \mathrm{H}$ NMR $(400 \mathrm{MHz}$, DMSO-d $): \delta 2.42(\mathrm{~s}, 3 \mathrm{H}), 2.88\left(1 \mathrm{H}, \mathrm{dd},{ }^{3} \mathrm{~J}=13.74,5.12 \mathrm{~Hz}\right), 3.06\left(1 \mathrm{H}, \mathrm{dd},{ }^{3} \mathrm{~J}=\right.$ 13.56, 4.04Hz), $4.32(1 \mathrm{H}), 6.43(\mathrm{~s}, 1 \mathrm{H}), 7.04-7.06(2 \mathrm{H}, \mathrm{d}, \mathrm{J}=7.32 \mathrm{~Hz}), 7.15-7.16(3 \mathrm{H}, \mathrm{t}, \mathrm{J}=7.32 \mathrm{~Hz})$, $7.51(2 \mathrm{H}, \mathrm{d}, \mathrm{J}=8.08 \mathrm{~Hz}), 7.82-7.84(2 \mathrm{H}, \mathrm{d}, \mathrm{J}=8.08 \mathrm{~Hz}), 8.55(\mathrm{~s}, 1 \mathrm{NH}), 10.29(\mathrm{~s}, 1 \mathrm{NH}) \mathrm{ppm} .{ }^{13} \mathrm{C} \mathrm{NMR}$ (100 MHz, DMSO-d 6 ): $\delta 21.74,39.74,56.26,119.33,122.14,123.38,127.29,128.49,128.56,130.46$, $131.80,135.59,135.68,146.68,158.09,165.54 \mathrm{ppm}$. Mass spectrum: direct insertion/MS; 386 molecular ion, $\mathrm{M}^{+}$.

\section{Synthesis of (E)-3-benzyl-6-((pyrrolidin-1-yl)methylene)piperazine-2,5-dione (2a)}

Tosylate 1 (384mg, $1.0 \mathrm{mmol})$ was added to a $25 \mathrm{ml}$ oven dried round-bottom glass flask. Distilled solvent dimethylformamide $8.5 \mathrm{ml}$ was added to dissolve the tosylate. To this stirring solution was added $414 \mu \mathrm{L}(5 \mathrm{mmol})$ of pyrrolidine and the contents were stirred at room temperature for $5 \mathrm{hrs}$. During the course of reaction the color of the solution changed from light brown at the beginning to a dark brown color indicating the completion. The homogenous solution mixture was quenched by slowly adding pre cooled ice water $(40 \mathrm{ml})$ and was set aside for solid formation. The obtained amorphous yellow tinted solid was filtered, further washed with cold water and air dried to give title 1,3diaminoethenyl product (2a), (114 mg) 40\% (isolated crude yield). An analytical sample is obtained by recrystallization from acetonitrile. M. Pt. $248-250{ }^{\circ} \mathrm{C} .[\alpha]_{\mathrm{D}}{ }^{22}=-250^{\circ}$ (c $\left.0.1, \mathrm{DMSO}\right)$

${ }^{1} \mathrm{H}$ NMR (400 MHz, DMSO-d 6 ): $\delta 1.72$ to 1.74 (multiplet, $8 \mathrm{H}$ ), $2.86\left(\mathrm{dd},{ }^{3} \mathrm{~J}=13.56,5.12 \mathrm{~Hz}, 1 \mathrm{H}\right.$ ), $2.91\left(\mathrm{dd},{ }^{3} \mathrm{~J}=12.28,6.9 \mathrm{~Hz}, 1 \mathrm{H}\right), 3.99(1 \mathrm{H}), 6.43(\mathrm{~s}, 1 \mathrm{H}), 7.15-7.21(\mathrm{~m}, 5 \mathrm{H}), 7.23(\mathrm{~s}, 1 \mathrm{H}), 8.9(\mathrm{~s}, 1 \mathrm{H})$ ppm. ${ }^{13} \mathrm{C}$ NMR (100 MHz, DMSO-d 6 ): $\delta$ 25.51, 39.22, 50.86, 56.95, 101.50, 126.84, 128.53, 129.83, $130.53,136.94,164.01,165.42 \mathrm{ppm}$. Mass spectrum: direct insertion/MS; 285 molecular ion, $\mathrm{M}^{+}$.

\section{Synthesis of (E)-3-benzyl-6-(piperidin-1-yl)methylene)piperazine-2,5-dione (2b)}

$0.0960 \mathrm{~g}$ (0.25 mmol.) starting Tosylate (1) was dissolved in the freshly distilled solvent $2.5 \mathrm{ml}$ dimethylformamide and to this solution Piperidine $138 \mu \mathrm{L}(1.375 \mathrm{mmol})$, was added in one portion

with stirring at room temperature for 10 hours. The characteristic color transition during the course of the reaction from the light brown color of the reaction mixture changed to a deep brown red coloration indicated the completion of the reaction. Product was isolated by quenching the reaction mixture in ice and allowed to precipitate within 30 minutes. The obtained yellow tinted solid was carefully washed with additional cold water, filtered and air dried to get 1,3-diaminoethenyl product (2b), in an isolated yield of (75 mg) $25 \%$. Melting Point $200{ }^{\circ} \mathrm{C}$ (red coloration).

${ }^{1} \mathrm{H}$ NMR (400 MHz, DMSO-d 6 ): $\delta$ 1.47-1.52 (Piperidine, broad multiplet), 2.86-3.06 (benzylic, 2H, ${ }^{3} \mathrm{~J}$ $=13.36,5.12 \mathrm{~Hz}), 4.02(1 \mathrm{H}), 6.19(\mathrm{~s}, 1 \mathrm{H}), 7.14-7.44(5 \mathrm{H}$, aromatics $), 7.62(\mathrm{NH})$, and $9.1(\mathrm{NH}) \mathrm{ppm} .{ }^{13} \mathrm{C}$ NMR (100 MHz, DMSO-d 6 ): $\delta$ 24.13, 25.83, 39.20, 51.10, 56.84, 102.79, 126.97, 128.01, 128.59, $130.39,131.22,136.81,163.90$, and 165.64 ppm. Mass spectrum: ESI/MS; $300.1[\mathrm{M}+\mathrm{H}]^{+}, 322.1$ $[\mathrm{M}+\mathrm{Na}]^{+}$ 
Synthesis of (E)-3-((dipropylamino)methylene)-6-benzyl piperazine-2,5-dione (2c)

Tosylate (1) (384mg, $1.0 \mathrm{mmol}$ ) was dissolved in the freshly distilled solvent dimethylformamide and to this solution the Dipropylamine (8 eq.) was added in one portion and this mixture was stirred at room temperature for 9 days. The solvent dimethylformamide was carefully distilled under reduced pressure and the reaction mixture was allowed to settle to room temperature and was quenched with cold water. The product was isolated from the aqueous mixture by allowing for precipitation after standing overnight at room temperature. The obtained yellow tinted solid was carefully filtered, washed with additional cold water and air dried to get 1,3-diaminoethenyl product (2c), in an isolated yield of (221 mg) $70 \%$. Melting Point. $220{ }^{\circ} \mathrm{C}$.

${ }^{1} \mathrm{H}$ NMR (400 MHz, DMSO-d 6 ): 80.81-0.93 (m, 6H), 1.59-1.64 (m, 6H), $2.51(2 \mathrm{H}), 2.91(\mathrm{~m}, 1 \mathrm{H}), 2.99$ $(\mathrm{m}, 1 \mathrm{H}), 3.96(1 \mathrm{H}), 6.4223(\mathrm{~s}, 1 \mathrm{H}), 7.32(\mathrm{~s}, \mathrm{NH}), 8.97(\mathrm{~s}, \mathrm{NH}), 7.18-7.26(\mathrm{~m}, 5 \mathrm{H}$, aromatics $) \mathrm{ppm} .{ }^{13} \mathrm{C}$ NMR (100 MHz, DMSO-d $)$ : $\delta$ 11.45, 22.46, 39.69, 54.76, 56.90, 100.27, 126.97, 128.78, 130.32, 137.11, 164.51, 165.90 ppm. Mass: direct insertion/MS; 315 molecular ion $\mathrm{M}^{+}$.

\section{((2-aminoethylamino)methylene)-6-benzyl piperazine-2,5-dione (2d)}

$0.0240 \mathrm{~g}(0.083 \mathrm{mmol})$ of the Tosylate $(\mathbf{1})$ was dissolved in $0.7 \mathrm{ml}$ of deuterated solvent dimethyl sulfoxide in a NMR tube and to this $25 \mu \mathrm{L}(4.5 \mathrm{mmol})$ of ethylenediamine was added in one portion and the reaction was followed using ${ }^{1} \mathrm{H}-\mathrm{NMR}$. The reaction was completed in 3 days with $100 \%$ conversion as judged by ${ }^{1} \mathrm{H}$ and ${ }^{13} \mathrm{C}$ NMR resonances (using dichloromethane as an internal standard) to give the product 1,3-diaminoethenyl (2d).

${ }^{1} \mathrm{H}$ NMR (400 MHz, DMSO-d 6 ): $\delta 2.20(\mathrm{~m}, 3 \mathrm{H}), 2.95(\mathrm{~m}, 1 \mathrm{H}), 2.81-2.98(1 \mathrm{H}), 3.02-3.06(1 \mathrm{H}), 4.18$ (t, J $1.19 \mathrm{~Hz}, 1 \mathrm{H}), 6.28(\mathrm{~d}, \mathrm{~J} 13.12 \mathrm{~Hz}, 1 \mathrm{H}), 7.14-7.23\left(5 \mathrm{H}\right.$, aromatics) ppm. ${ }^{13} \mathrm{C} \mathrm{NMR}(100 \mathrm{MHz}$, DMSO- $\left.\mathrm{d}_{6}\right): \delta 40.26,45.60,51.68,56.49,101.01$ 128.65, 130.15, 130.52, 136.93, 146.11, 161.57, $164.57 \mathrm{ppm}$.

\section{(E)-3-benzyl-6-((piperazin-1-yl)methylene)piperazine-2,5-dione (2e)}

$0.024 \mathrm{~g}(0.085 \mathrm{mmol})$ of Tosylate (1) was taken in a NMR tube and added $0.7 \mathrm{ml}$ of NMR solvent DMSO- $\mathrm{d}_{6}$ to dissolve. Piperazine $(0.23 \mathrm{mmol})$ was added in one portion and dissolved in the tube. The reaction was monitored using ${ }^{1} \mathrm{H}-\mathrm{NMR}$ with dichloromethane as an internal standard. Conversion to $100 \%$ of 1,3-diaminoethenyl product (2e), was complete in 6 hours of reaction time.

${ }^{1} \mathrm{H}$ NMR (400 MHz, DMSO-d $\mathrm{d}_{6}$ ): $\delta 2.28$ to 3.0 (piperazinyl product signals overlap with DMSO- $\mathrm{d}_{6}$ ), 2.67, 2.73, $4.18(\mathrm{t}, \mathrm{J}=16 \mathrm{~Hz}) 6.13(\mathrm{~s}), 7.13-7.21 \mathrm{ppm}$ (aromatics) ppm. ${ }^{13} \mathrm{C}$ NMR (100 MHz, DMSO$\left.\mathrm{d}_{6}\right): \delta 33.90,48.13,51.90,56.84,103.24,126.07,128.17,130.32,130.41,136.74,146.13,163.74$, $165.64 \mathrm{ppm}$.

\section{Synthesis of (E)-3-((tert-butylamino)methylene)-6-benzylpiperazine-2,5-dione (2f)}

$0.096 \mathrm{~g}(0.25 \mathrm{mmol})$ of the starting Tosylate (1) was dissolved in the freshly distilled solvent dimethylformamide and to this solution the freshly distilled tert-butylamine ( $3 \mathrm{mmol})$ was added in one portion with stirring and maintained at gentle reflux for 1.5 hours. The reaction mixture was allowed to settle to room temperature and was quenched with cold water. The product was isolated by allowing for precipitation overnight standing at room temperature. The obtained brown solid was carefully filtered, washed with additional cold water and air dried to get the 1,3-diaminoethenyl product (2f), (43 $\mathrm{mg}$ ) yield $60 \%$. Melting point $240{ }^{\circ} \mathrm{C}$.

${ }^{1} \mathrm{H}$ NMR (400 MHz, DMSO-d 6 ): $\delta 1.08(\mathrm{~s}, 9 \mathrm{H}), 2.72(1 \mathrm{H}), 2.89(1 \mathrm{H}), 4.19(1 \mathrm{H}), 6.37-6.40(\mathrm{~d}, \mathrm{~J}=$ 13.2Hz, 1H), 7.16-7.18 (2H), 7.21-7.22 (3H), 7.26 (s, NH), 8.31(s, NH), 9.22 (s, NH) ppm. ${ }^{13} \mathrm{C}$ NMR (100 MHz, DMSO-d 6 ): $\delta 30.29,39.20,50.88,55.75,100.71,122.67,26.37,127.84,129.91,136.34$, 160.78, 163.89 ppm. Mass: GC/MS; 287 molecular ion, $\mathrm{M}^{+}$. 
Synthesis of (E)-3-((anilino)methylene)-6-benzylpiperazine-2,5-dione (2g)

$0.0960 \mathrm{~g}(0.25 \mathrm{mmol})$ the starting Tosylate (1) was dissolved in the freshly distilled solvent $2.4 \mathrm{ml}$ dimethylformamide and to this solution the aniline $228 \mu \mathrm{L}(2.5 \mathrm{mmol})$ was added in one portion and was stirred and maintained at gentle reflux for 6 hours. The reaction mixture was then allowed to settle to room temperature and was quenched with cold water. The product was isolated by allowing the precipitation of a brown solid after standing at room temperature. The brown solid was carefully filtered, washed with additional cold water and air dried to get the 1,3-diaminoethenyl product (2g), yield $(64.5 \mathrm{mg}) 84 \%$. Melting point $225-230{ }^{\circ} \mathrm{C}$.

${ }^{1} \mathrm{H}$ NMR (400 MHz, DMSO-d $)$ : $\delta$ 2.91-3.16 (m,2H), $4.32(1 \mathrm{H}), 6.78(\mathrm{~d}, 1 \mathrm{H}, \mathrm{J}=14.64 \mathrm{~Hz}), 6.85-6.86$

$(\mathrm{m}, 4 \mathrm{H}), 7.20-7.24(\mathrm{~m}, 6 \mathrm{H}), 7.86(1 \mathrm{H}, \mathrm{NH}), 8.28-8.31(1 \mathrm{H}, \mathrm{NH}), 9.55(1 \mathrm{H}, \mathrm{NH}), \mathrm{ppm} .{ }^{13} \mathrm{C}$ NMR $(100$ MHz, DMSO-d $)_{6}: \delta 39.20,56.46,106.19,114.28,120.98,127.10,127.26,128.53,129.34,130.17$, 130.57, 136.53, 142.37, 160.76, 165.02 ppm. Mass: GC/MS; 307 molecular ion, $\mathrm{M}^{+}$.

\section{Synthesis of (E)-3-benzyl-6-((butylthio)methylene)Piperazine-2,5-dione (2h)}

$0.096 \mathrm{~g}(0.25 \mathrm{mmol})$ of tosylate (1) was added to a $25 \mathrm{ml}$ oven dried round bottom flask and dissolved in distilled dimethylformamide. $326 \mu \mathrm{L}(3 \mathrm{mmol})$ of Butanethiol was added in one portion and the contents of the flask were brought to a temperature of $110^{\circ} \mathrm{C}$ and maintained for 6 days with stirring. The solvent was removed and the contents of the flask were brought to room temperature, quenched with $10 \mathrm{ml}$ of distilled water and after overnight standing product thioenamine (2h) precipitated, yield $(22.8 \mathrm{mg}) 30 \%$. Melting Point. $165^{\circ} \mathrm{C}$ (red coloration completely melts at $175^{\circ} \mathrm{C}$ ). ${ }^{1} \mathrm{H}$ NMR (400 MHz, DMSO-d 6 ): $\delta$ 0.85-0.88 (t, 3H, J = 4Hz), $1.37(\mathrm{~m}, 2 \mathrm{H}), 1.49(\mathrm{~m}, 2 \mathrm{H}), 2.71(\mathrm{~m}$, 2H), $2.97(1 \mathrm{H}), 2.99(1 \mathrm{H}), 4.39(1 \mathrm{H}), 6.16(1 \mathrm{H}), 7.14-7.23(\mathrm{~m}, 5 \mathrm{H}), 8.21(\mathrm{~s}, \mathrm{NH}), 9.45(\mathrm{~s}, \mathrm{NH}) \mathrm{ppm}$. ${ }^{13} \mathrm{C}$ NMR (100 MHz, DMSO-d $\left.{ }_{6}\right): \delta 13.98,21.45,39.53,39.95,56.60,115.0,124.86,127.19,128.56$, $129.26,130.54,136.08,158.42,165.83$ ppm. Mass: GC/MS; 304 molecular ion $\mathrm{M}^{+}$.

\section{References}

1. Dawid Siodłak (2015) $\alpha, \beta$-Dehydroaminoacids in Naturally Occurring Peptides. Amino Acids, 47, 1-17.

2. Berer N., Ruidi A., Goldberg I., Benayahu Y., and Kashman Y. (2004) Callynormine A, a New Marine Cyclic Peptide of a Novel Class. Org. Lett., 6 (15) 2543-2545.

3. Dierks T., Miech C., Hummerjohann, J., Schmidt, B., Kertsez, M.A., and von Figura, K. (1998) Posttranslational Formation of Formylglycine in Prokaryotic Sulfatases by Modification of Either Cysteine or Serine. J.Biol. Chem., 273 (40) 25560-25564.

4. Fraldi A., Biffi A., Lombardi A., Visigalli I., Pepe S., Settembre C., Nusco E., Auricchio A., Naldini L., Ballabio A., and Cosma MP. (2007) SUMF1 enhances sulfatase activities in vivo in five sulfatase deficiencies. Biochem. J., 403 (7) 305-12.

5. Diez-Roux G., and Ballabio A. (2005) Annual Review of Genomics and Human Genetics, 6 355-379 (DOI: 10.1146/annurev.genom.6.080604.162334).

6. Schulze H., and Sandhoff K., Cold Spring Harb Perspect Biol, (DOI: 10.1101/ cshperspect. a004804).

7. Nakazawa T., Suzuki T., and Ishii M. (1997) Synthesis and Characterization of $\beta-O-$ Tosyldehydroserine as a Precursor of Dehydroamino Acids. Tetrahedron Lett., 38 (52) 89518954

8. Pappo D., Vartanian M., Lang S., and Kashman Y. (2005) Synthesis of Cyclic Endiamino Peptides. J. Am. Chem. Soc., 127 (21) 7682-7683.

9. Pappo D., and Kashman Y. (2006) $\beta$-Turn Mimetic: Synthesis of Cyclic Thioenamino Peptides. Org. Lett., 8 (6) 1177-1179.

10. Singh et al (2003) Cysteine Protease Inhibitors. U.S. Patent 6, 635, 621, B1. 
11. Bhavaraju S., McGregor M.A., and Rosen W. (2007) Nucleophilic reactivity of amines with an $\alpha$-formylgycyl enol-tosylate. Tetrahedron Lett., 48 (44) 7751-7755. 